East African Medical Journal Vol. 81 No. 3 March 2004

THE FIRST SIX MONTH GROWTH AND ILLNESS OF EXCLUSIVELY AND NON-EXCLUSIVELY BREAST-FED INFANTS IN NIGERIA

A. A. Onayade, MBBS., MPH., FWACP., FMCPH., Senior Lecturer, T. C. Abiona, MBChB., FMCPH., Lecturer, I. O. Abayomi, MBBS., DTPH., FMCPH., FWACP., Reader and R. O. A. Makanjuola, BSc., MBBS, M. Phil., PhD., MRCPsych., FMCPsych., FWACP (Psych), Professor and Vice-Chancellor, Obafemi Awolowo University, Ile-Ife, Nigeria

Request for reprints to: Dr. A. A. Onayade, P.O. Box 918, lle-lfe, Nigeria

\title{
THE FIRST SIX MONTH GROWTH AND ILLNESS OF EXCLUSIVELY AND NON-EXCLUSIVELY BREAST-FED INFANTS IN NIGERIA
}

\author{
A. A. ONAYADE, T. C. ABIONA, I. O. ABAYOMI \\ and R. O. A. MAKANJUOLA
}

\begin{abstract}
Objective: To compare the growth and illness pattern of infants who were exclusively breast fed for six months with those of infants commenced on complementary feeding before the age of six months and ascertain reasons for the early introduction of complementary feeding.

Design: A comparative prospective study.

Setting: Urban Comprehensive Health Centre (UCHC), Obafemi Awolowo University Teaching Hospitals Complex, lle-lfe.

Subjects: Three hundred and fifty-two mothers and their normal birth weight babies, weighing $2.500 \mathrm{~kg}$ or more, and aged less than 14 days were serially recruited into the study.

Main outcome measures: Mean/median monthly weights in the first six months of life, history/outpatient presentation for illnesses.

Results: Of the 352 mother-infant pairs recruited into the study, $345(98 \%)$ were successfully followed up for the first six months of life. At six months, 264 (76.5\%) were exclusively breast-fed, $45(13.1 \%)$ were started on complementary feeding, between the ages of four and six months while $36(10.4 \%)$ commenced complementary feeding before the age of four months. Infants who were exclusively breast-fed for six months had median weights above the 50th percentiles of the WHO/NCHS reference that is currently used in the national "road to health" (growth monitoring) cards. Furthermore, the mean weight of these babies at age six months was above those of babies who started complementary foods before six months. They also reported fewer symptoms and had fewer illness episodes (0.l episodes per child) compared to those who started complementary feeding before six months. Infants who commenced complementary feeding before four months reported more symptoms and had more illness episodes (1.4 episodes per child) compared to those that commenced complementary feeding between four and six months (1.2 episodes per child). Common symptoms/illnesses seen or reported during the study among the groups were fever, diarrhoea and cough. Reasons given for early introduction of complementary foods include insufficient breast milk, thirst and convenience.

Conclusion: It is concluded that exclusive breast-feeding supported adequate growth during the first six months of life for most of the infants studied. Early introduction of complementary foods did not provide any advantages in terms of weight gain in our environment, it was frequently associated with illness episodes and growth faltering. Many mothers however require support, encouragement and access to health care providers to breastfeed exclusively for the first six months of life.
\end{abstract}

\section{INTRODUCTION}

The marked disparity in infant mortality between developed and developing countries is a cause of global concern and reduction of infant mortality remains a major challenge in developing countries including Nigeria where about $114 / 1000$ children aged 0-12 months die yearly from various causes(1). Common causes of deaths among these infants include preventable conditions such as acute respiratory infection (ARI), diarrhoeal diseases, malaria, anaemia and other infectious diseases with malnutrition as a frequent and important underlying cause(2). In an effort to reduce the unacceptably high infant deaths in the developing countries, the United Nations Children's Fund (UNICEF) and World Health Organization (WHO) introduced the "Child Survival Strategies" in 1978. These strategies consisting of growth monitoring and promotion (GMP); 
oral rehydration therapy (ORT); promotion of breastfeeding; immunization; family planning; food and appropriate nutrition and female education (GOBIFFF) have received strong national and international promotion as cheap, highly effective and sustainable strategies for developing countries(3).

Breast-feeding has been acknowledged as the most important of the child survival strategies as it is intimately related to all the other strategies. Globally, it is estimated that about one million infant deaths can be prevented annually by the adoption of correct breastfeeding practices(4). Thus, a world summit for children held in Florence, Italy, in 1990, adopted the Innocenti Declaration for the promotion, protection and support for breast-feeding through the Baby Friendly Hospital Initiative (BFHI). The two broad objectives of the initiative are: (a) the promotion of exclusive breastfeeding for the first six months of life and (b) continuation of breast-feeding with adequate and appropriate locally available complementary foods till the age of two years.

Evidence from several studies suggests that breastfeeding exclusively for the first six months of life supports optimal growth with the lowest risks of infection and ill health(5-9). The acquisition of the many antiinfective agents in colostrum and breast milk provides protection for the young infant against infective agents while the elimination of exposure of the young infant to contaminated foods and drinks provides added advantage(10). Exclusive breast-feeding for the first six months of life however conflicts with local knowledge in our environment and mothers frequently start complementary feeding before the age of six months. Furthermore, health workers who are expected to implement the policy have expressed reservations about the recommendation doubting the ability of many mothers from developing countries to provide sufficient breastmilk to support adequate growth during the first six months of life. To ascertain that normal birth weight infants (NBW), weighing $2.500 \mathrm{~kg}$ or more, are able to achieve adequate growth in the first six months of life on their mothers' breast milk alone irrespective of the mother's social, demographic or anthropometric status, and assess the advantages or otherwise of introducing complementary feeding before six months in our environment, this study therefore compared growth and illness pattern of exclusively and non-exclusively breastfed infants during the first six months of life. To obtain a clearer understanding of the advantages or otherwise of complementary feeding before six months, infants introduced to complementary feeding before six months were sub-grouped into those commencing complementary feeding before four months and those commencing complementary feeding between four and six months.

\section{MATERIALS AND METHODS}

This prospective study was conducted at the Urban Comprehensive Health Centre (UCHC), Obafemi Awolowo University Teaching Hospitals Complex, lle-lfe. Mothers and their babies aged 14 days or less and who weighed 2.5 $\mathrm{kg}$ and above were recruited into the study from mission hospitals and immunization clinics of all the major government health facilities in Ile-lfe. All recruited mothers and their babies were followed up for a period of six months using UCHC as the base for the study. The mean ambient temperature in this part of Nigeria oscillates between $25^{\circ} \mathrm{C}$ and $40^{\circ} \mathrm{C}$. In order to encourage participation in the study mothers were introduced to the study during the last trimester of pregnancy through formal health education sessions that were normally held in the antenatal clinics. The inclusion criteria were: (a) mothers whose babies weighed $2.5 \mathrm{~kg}$ or more during the first two weeks of life and who consented to participate in the study. Excluded from the study were: (a) mothers who had multiple births, (b) babies with any form of congenital abnormality, (c) any mother who exclusively bottle-fed or who fed her baby exclusively on infant formula or breast-milk substitutes in the first six months of life, (d) pre-term and (e) low birth weight babies (weighing less than $2.5 \mathrm{~kg}$ ).

Sample size for the study was determined using the highest standard deviation of $0.93 \mathrm{~kg}$ as obtained by Zumrawi and Diamond(11) for infants aged six months in a study conducted in Sudan. Accepting a $90 \%$ confidence level and an error rate of 0.1 , a minimum sample size of 235 subjects was determined. This figure was however increased to 350 to compensate for recruited mothers who would introduce complementary feeding before the age of six months and those who would voluntarily drop out of the study for one reason or another. Eligible mothers who accepted to participate were therefore recruited into the study serially until the desired sample size was attained.

Prior to data collection, ethical clearance for the study was obtained from the Ethical Committee of the Obafemi Awolowo University Teaching Hospitals Complex, lle-lfe. For ethical reasons, all mothers were encouraged to breastfeed exclusively for the first six months of life in line with our national guidelines. All mothers were thus counselled on the benefits of breast-feeding and mothers who accepted to participate in the study were also counselled on the purpose and demands of the study. In addition, consenting mothers were informed about the importance of providing correct and accurate information to the researchers during enrolment and follow-up on the mode of feeding and occurrence of symptoms of illnesses. Mothers were also informed that if they voluntarily decided to introduce complementary feeding at anytime before six months, their decision would be respected, and that they would not be removed from the study and would continue to enjoy all privileges provided in terms of followup. More importantly, no mother- suffered any disadvantages as a result of refusal to participate in the study. In this regard, all mothers and their babies aged 0-6 months were attended to as a matter of priority throughout the duration of the study by the researchers or other resident doctors in the department of Community Health who functioned as research assistants. 
Information was collected from consenting mothers with the aid of a purpose-designed interview schedule. The schedule was administered at enrolment by the researchers or the research assistants. Follow-up information on weights, history of illnesses and other relevant pieces of information were recorded on the follow-up charts that were maintained for each enrolled child. To cross-check the authenticity of the pieces of information provided by mothers on mode of feeding, the researchers or assistants paid one or more unannounced home visits to every participating mother during the first three months of enrolment and at least once in the last three months.

Monthly weight measurements were made using a digital electronic solar weighing scale (Seca ${ }^{\circledR}$ Uniscale, Model 890, manufactured in Australia). Infants were weighed on the day of recruitment and subsequently monthly (every 27 to 33 days) by the researchers or research assistants. Babies were weighed nude and only one measurement was taken. Although the scale checks for zero error automatically, validation of measurements was achieved by regularly weighing two heavy metal objects that were kept for this purpose. All infants were managed for any reported illnesses by the researchers or research assistants. All had earlier received training concerning the weighing and recording of baseline and follow-up information.

Statistical analysis of the data was carried out with a personal computer using appropriate software and the results presented with tables and graphs. Comparison of continuous variables was by means of the students t-test while categorical variables were compared with the Chi-square test. For all tests, a P-value of less than $5 \%$ was accepted as statistically significant.

\section{RESULTS}

Three hundred and fifty two mother/baby pairs were recruited into the study; 68(19.3\%) were recruited during the first week of life while $284(80.7 \%$ ) were recruited during the second week of life. Of these, $345(98 \%)$ were successfully followed up until the infants were six months old while seven $(2 \%)$ of the mothers were lost to follow up. Two hundred and sixty four $(76.5 \%)$ of the 345 babies were breast-fed exclusively for the first six months of life while 81 $(23.5 \%)$ were introduced to complementary feeding before the age of six months. Table 1 compares the social and demographic characteristics of the mothers who breastfed exclusively and those who introduced complementary feeding before six months. Mothers in the 30-39 year age group were more likely to breastfeed exclusively for the first six months of life compared to the other age groups $(\mathrm{P}=0.036)$. Concerning marital status, mothers who were married and living with their spouses were more likely to breast-feed exclusively for the first six months of life $(\mathrm{P}=0.009)$ while mothers who were unemployed (kept home) were more likely to introduce complementary feeding before six months $(\mathrm{P}=0.001)$. Similarly, mothers who were nursing their first babies were more likely to start their infants on complementary feeding before six months compared to those who had had other babies $(\mathrm{P}=0.019)$.
Pertaining to the place of delivery of the babies, 144(40.9\%) were delivered in government hospitals, 97 $(27.3 \%)$ in mission houses, $68(19.3 \%)$ in private hospitals, $26(7.4 \%)$ at home, $14(4.0 \%)$ in primary health centres and three $(0.9 \%)$ in the homes of traditional birth attendants.

Table 2 shows the main complementary feed introduced to the 81 babies by age. Eleven babies (13.5\%) were introduced to complementary feeding during the first three months of life while the remaining $70(86.5 \%)$ were introduced to complementary feeding from the fourth to the sixth month. Concerning the main form of complementary feeding introduced to the babies, water was the more frequently introduced feed in the first three months of life while local or prepackaged cereal and infant formula were more frequently introduced from the fourth to sixth month.

Table 3 explores the main reasons provided by the mothers for introducing complementary feeding. 'Thirst' was the more frequently given reason for introducing complementaly feeding during the first three months of life while inadequate growth due to insufficient breast-milk, "child old enough to start complementary feeding" and convenience were more cited for introducing complementary feeding from the fourth to sixth month of life.

With regard to the symptoms or illness episodes reported or seen among the babies during the first six months of life, the 36 babies introduced to complementary feeding before four months had a total of 50 illness episodes ( 1.4 episodes per child). Of these, $45(90 \%)$ episodes were due to fever, diarrhoea and ARI (cough or other respiratory symptoms). For the 45 babies introduced to complementary feeding between four and six months of life, 52 illness episodes (1.2 episodes per child) were recorded of which, 48 (92.3\%) were due to fever, diarrhoea and ARI. Babies who were exclusively breast-fed for six months had fewer illness episodes, 41 episodes among the 345 babies ( 0.1 episodes per child). Of these episodes, 30(73.2\%) were due to fever, ARI and diarrhoea. The relative risk (RR) for fever, diarrhoea and cough among babies commenced on complementary feeding before six months were: for diarrhoea, 44(95\% C.I. $=10.3-188.7)$ for those commenced on complementary feeding before four months and 46.9(95\% C.I=11.2-197.2) for those commenced on complementary feeding between four and six months. For fever, RR was $13.5(95 \%$ C.1.=7.6-24.1) and 11.7(95\% C.I.=8.5-21.1) for those commenced on complementary feeding before four months and those commenced on complementary feeding between four and six months respectively. For ARI, RR was $4.4(95 \%$ C.1 $=2.1-9.3)$ and $2.3(95 \%$ C.1.=I-5.73) for the babies commenced on complementary feeding before four months and those commenced on complementary feeding between four and six months respectively. 
Table 1

Social and demographic characteristics of the mothers successfully followed up for six months

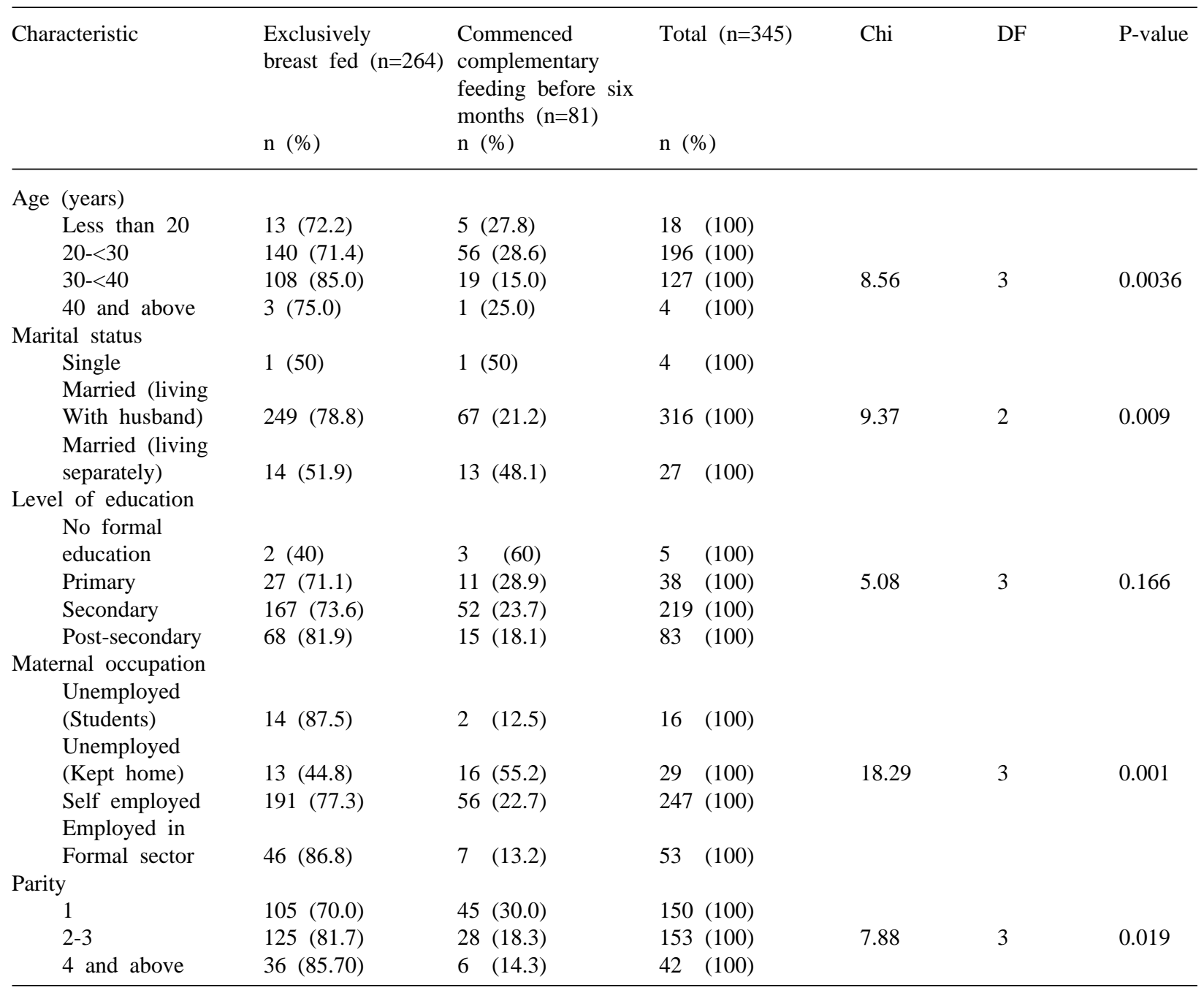

Table 2

Main complementary feed introduced by age

\begin{tabular}{|c|c|c|c|c|c|}
\hline \multirow[t]{2}{*}{ Age (months) } & \multicolumn{4}{|c|}{ Complementary feed } & \multirow[t]{2}{*}{ Total } \\
\hline & Local Cereal & Infant formula & Water & $\begin{array}{l}\text { Pre-packaged } \\
\text { cereal }\end{array}$ & \\
\hline $0-<1$ & 1 & 0 & 3 & 0 & 4 \\
\hline $1-<2$ & 1 & 0 & 2 & 0 & 3 \\
\hline $2-<3$ & 1 & 0 & 3 & 0 & 4 \\
\hline $3-<4$ & 13 & 4 & 4 & 4 & 2.5 \\
\hline $4-<5$ & 12 & 15 & 5 & 6 & 38 \\
\hline $5-<6$ & 1 & 4 & 2 & 0 & 7 \\
\hline Total & 29 & 23 & 19 & 10 & 81 \\
\hline
\end{tabular}


Table 3

Main reasons offered by mothers for introduction of complementary feeding before six months by age

\begin{tabular}{|c|c|c|c|c|c|c|}
\hline \multirow{2}{*}{$\begin{array}{l}\text { Age } \\
\text { (months) }\end{array}$} & \multicolumn{6}{|c|}{ Reasons } \\
\hline & $\begin{array}{l}\text { Insufficient breast- } \\
\text { milk or inadequate growth }\end{array}$ & Thirst & Convenience & $\begin{array}{l}\text { "Child old } \\
\text { enough" }\end{array}$ & $\begin{array}{l}\text { Mother-in- } \\
\text { law insisted }\end{array}$ & Total \\
\hline 0 & 2 & 2 & - & - & - & \\
\hline 1 & 1 & 1 & 1 & - & - & \\
\hline 2 & 2 & 2 & - & - & - & \\
\hline 3 & 11 & 5 & 5 & 4 & - & \\
\hline 4 & 20 & 6 & 5 & 6 & - & \\
\hline 5 & 5 & 1 & - & 1 & 1 & \\
\hline Total $(\%)$ & $41(50.6)$ & $17(21.0)$ & 11 (13.6) & 11 (13.6) & 1 (1.2) & $81(100)$ \\
\hline
\end{tabular}

Table 4

Mean monthly weights of the boys during the first six months of life

\begin{tabular}{|c|c|c|c|c|c|c|}
\hline \multirow[t]{3}{*}{$\begin{array}{l}\text { Age } \\
\text { (months) }\end{array}$} & \multicolumn{3}{|c|}{ Mean weights (S.D.) Kg } & \multicolumn{3}{|c|}{$\begin{array}{c}\text { P-values of differences between } \\
\text { the groups }\end{array}$} \\
\hline & 1 & 2 & 3 & $1 \mathrm{vs}$ & & $2 \mathrm{vs} 3$ \\
\hline & $\begin{array}{l}\text { Commmenced on } \\
\text { complementary } \\
\text { feeding before } \\
\text { four months } \\
(n=16)\end{array}$ & $\begin{array}{l}\text { Commenced on } \\
\text { complementary } \\
\text { feeding between } \\
\text { four and six months } \\
(\mathrm{n}=18)\end{array}$ & & $\begin{array}{r}\text { Commence } \\
\text { bre } \\
\text { si } x\end{array}$ & Isively & \\
\hline 0 & $3.156(0.388)$ & $3.400(0.460)$ & $3.243(0.406)$ & $>0.05$ & $>0.05$ & $>0.05$ \\
\hline 1 & $4.380(0.466)$ & $4.561 \quad(0.581)$ & $4.573(0.613)$ & $>0.05$ & $>0.05$ & $>0.05$ \\
\hline 2 & $5.269(0.357)$ & $5.456(0.721)$ & $5.725(0.754)$ & $>0.05$ & $>0.01$ & $>0.05$ \\
\hline 3 & $6.106(0.475)$ & $6.347(0.734)$ & $6.725(0.754)$ & $>0.05$ & $>0.01$ & $>0.05$ \\
\hline 4 & $6.727(0.550)$ & $7.000(0.704)$ & $7.631(0.826)$ & $>0.05$ & $>0.01$ & $<0.01$ \\
\hline 5 & $7.075(0.676)$ & $7.505(0.765)$ & $8.496(0.883)$ & $>0.05$ & $<0.01$ & $<0.01$ \\
\hline 6 & $7.444(0.677)$ & $7.942(0.888)$ & $9.276(0.995)$ & $>0.05$ & $<0.01$ & $<0.01$ \\
\hline
\end{tabular}

Table 5

Mean monthly weights of girls during the first six months of life

\begin{tabular}{|c|c|c|c|c|c|c|}
\hline \multirow[t]{3}{*}{$\begin{array}{l}\text { Age } \\
\text { (months) }\end{array}$} & \multirow{2}{*}{$\begin{array}{l}\text { Mean weights }(\mathrm{SD}) \\
1\end{array}$} & \multirow[t]{2}{*}{$\mathrm{Kg}$} & \multirow[b]{2}{*}{3} & \multicolumn{3}{|c|}{$\begin{array}{l}\text { P-values of differences between } \\
\text { the groups }\end{array}$} \\
\hline & & & & 1vs & 1vs3 & $2 \mathrm{vs} 3$ \\
\hline & $\begin{array}{l}\text { Commenced on } \\
\text { complementary } \\
\text { feeding before } \\
\text { four months } \\
(\mathrm{n}=16)\end{array}$ & $\begin{array}{l}\text { Commenced on } \\
\text { complementary } \\
\text { feeding between } \\
\text { four and six months } \\
(\mathrm{n}=16)\end{array}$ & $\begin{array}{l}\text { Exclusively } \\
\text { breast-fed for } \\
\text { six months } \\
(n=133)\end{array}$ & & & \\
\hline 0 & $3.030(0.506)$ & $3.252(0.425)$ & $3.203(0.433)$ & $>0.05$ & $>0.05$ & $>0.05$ \\
\hline 1 & $3.960(0.717)$ & $4.404(0.571)$ & $4.408(0.573)$ & $>0.05$ & $>0.05$ & $>0.05$ \\
\hline 2 & $4.728(0.685)$ & $5.400(0.761)$ & $5.484(0.732)$ & $<0.01$ & $<0.01$ & $>0.05$ \\
\hline 3 & $5.537(0.859)$ & $6.263(0.722)$ & $6.418(0.828)$ & $<0.01$ & $<0.01$ & $>0.05$ \\
\hline 4 & $6.105(0.795)$ & $6.881(0.816)$ & $7.289(0.895)$ & $<0.01$ & $<0.01$ & $>0.05$ \\
\hline 5 & $6.579(0.763)$ & $7.233(0.809)$ & $8.062(0.946)$ & $<0.05$ & $<0.01$ & $<0.01$ \\
\hline 6 & $7.215(0.849)$ & $7.567(0.845)$ & $8.764(1.020)$ & $<0.05$ & $<0.01$ & $<0.01$ \\
\hline
\end{tabular}


Table 4 shows the mean monthly weights of boys during the first six months of life. Although the mean weights of the babies were comparable at birth and one month $(\mathrm{P}>0.05)$, from the age of two months through to six months, exclusively breastfed babies had mean monthly weights that were higher than those of babies that commenced complementary feeding before four months. For the babies commenced on complementary feeding between four and six months, the mean monthly weights of the babies were comparable for the first three months, subsequently, the mean monthly weights of exclusively breast-fed babies were higher from the fourth month to the sixth month $(\mathrm{P}<0.05)$. In addition, from the third month, babies started on complementary feeding between four and six months were also heavier than those started on complementary feeding before four months $(\mathrm{P}<0.05)$.

Among the girls (Table 5), all the three groups had comparable mean birth weights $(\mathrm{P}>0.05)$, however from the age of one month, girls exclusively breastfed for six months had higher mean monthly weights compared to those commenced on complementary feeding before four months $(\mathrm{P}<0.05)$. Similarly, at five and six months girls who were breast-fed exclusively for six months were heavier than those that commenced complementary feeding between four and six months. In addition, from the age of two to six months, girls commenced on complementary feeding between four and six months were heavier than those commenced on complementary feeding before four months $(\mathrm{P}<$ 0.05). Also, infants (both sexes) who were exclusively breast-fed for six months had median weights above the 50th percentiles of the WHO/NCHS reference that is currently used on our national "road to health" (growth monitoring) cards.

\section{DISCUSSION}

Exclusive breastfeeding, feeding an infant on only breast milk and no other liquids or solids with the exception of drops or syrups consisting of vitamins, for the first $4-6$ months of life is a key recommendation of the global Baby Friendly Hospital initiative (BFHI). There is strong agreement worldwide on the benefits of breast-feeding especially in environments where sanitation is poor $(6,8,12,13)$, however, there is debate on the optimal time for the introduction of complementary foods $(13,14)$. Currently, the Nigerian national BFHI recommends that complementary foods be introduced from the age of six months but doubts have been expressed locally as to the sufficiency of exclusive breast-feeding to support adequate growth during the first six months of life in our environment. Davies-Adetugbo(15), observed in a study conducted in this same local area that the concept of exclusive breast-feeding posed the greatest conflict between local knowledge and WHO/UNICEF breast-feeding recommendations. Locally, nursing mothers, particularly those from rural areas, are perceived as having borderline or poor nutritional status and their diet is inadequate in terms of nutrient intake. Concerns have therefore been expressed about the ability of such mothers to produce breast-milk of adequate nutritional quality and in sufficient quantity to support adequate growth of infants in the first six months of life. Concerns have similarly been expressed about the need for water supplementation though such concerns are not, however, limited to our environment as Sachdev et al.(16) reported that a significant proportion of health workers (doctors and nurses) in India believed that water supplementation was necessary under certain climatic conditions.

Several studies that related lactation performance of nursing mothers to their social, demographic or anthropometric status have concluded that these factors have limited impact on breast-milk output in terms of quantity or quality(17-20). Nevertheless, determining an optimal timing for introduction of complementary feeding is important to achieve optimal growth and development in the first year of life.

The findings of this study agree with the observation of other workers(21-23), that exclusively breast-fed infants gained adequate weight during the first six months of life. The mean of monthly weights of exclusively breast-fed boys and girls increased from birth to six months and no faltering was observed. From one month, the mean monthly weights of these babies were either comparable or higher than for babies commenced on complementary feeding before four months and those that commenced complementary feeding between four and six months.

The mean weight of the babies who commenced complementary feeding before the age of four months was slightly lower at recruitment than those of the other groups. While it is not certain if the mothers of these babies commenced them on complementary feeding because they perceived them to be lighter than their peers, early introduction of complementary feeding probably only worsened the infants' condition by predisposing them to frequent illness episodes; it provided no advantages in terms of weight gain. If anything, these babies reported more symptoms and had more frequent illness episodes necessitating visits to the health centre compared to the other babies. This probably also contributed to the lower rate of monthly weight gain.

Infants commenced on complementary feeding between four and six months on the other hand were slightly heavier at recruitment compared to their exclusively breast-fed counterparts but their mean monthly weight gain from one month was below that of their exclusively breastfed counterparts. Again while it is not certain if the mothers of these infants commenced complementary feeding because they perceived them to be gaining weight at a lower rate compared to their exclusively breast-fed peers, the 
introduction of complementary feeds was not really beneficial since the infants had more frequent illness episodes with the commencement of complementary feeding and the gap between their mean monthly weight compared to those of their exclusively breastfed counterparts continued to widen.

Complementary feeding in our environment includes the use of various food items such as infant formula, local cereal (pap), water and pre-packaged cereal (e.g. Cerelac, Babeena, Nutrend) with different energy contents. The mode of preparation of these foods would certainly not match the standards in developed countries in terms of nutritional quality and the level of hygiene observed in their preparation. This probably explains why the infants starting complementary feeding early in this study were worse off in terms of illness episodes and weight gain. Various reasons were given by mothers for starting complementary foods before the age of six months. In agreement with a study conducted in Jos by Ogbonna et al.(24) insufficient breastmilk was also the commonest reason given for introducing complementary feeding in this study; this is also consistent with finding from other parts of the world(5). Thirst, convenience, inadequate growth were the other common reasons given for early introduction of complementary feeding.

That the mean monthly weight of the infants in this study were consistently higher than those reported by other workers is probably due to the fact that not only were the mothers in this study encouraged to breastfeed exclusively but also on demand. Mothers were instructed to nurse the baby for any form of discomfort and the use of pacifiers was totally discouraged. Furthermore, all the mothers had improved access to health workers and health care including immunisation throughout the study period in addition to regular counselling and encouragement on breastfeeding. The contribution of these factors to the very favourable outcome concerning weight gain must have been significant though difficult to assess. Even mothers who introduced complementary feeding before six months were encouraged to continue breastfeeding inclusively and it is not certain to what extent this affected the breastfeeding practices or the number of mothers that would have stopped breast-feeding altogether without the support and encouragement provided.

The findings of this study agree with the observation by Juez et al.(5) and Cohen et al.(25) that hospitalisation, diarrhoea, anaemia and respiratory illnesses were rare events in infants exclusively breast-fed for six months. It is possible that infants introduced to complementary foods before six months of age reported more symptoms/ illnesses because of contamination of the food items including the use of unsafe water for food preparation and unhygienic handling of the foods. This in turn affected their weight gain, and resulted in a vicious cycle of early complementation, more illness and inadequate weight gain. The findings also support the conclusion by Cohen et al.(25) that there is no advantage in introducing complementary foods before six months in poor population and that there may be disadvantages if there is increased exposure to contaminated weaning foods.

In conclusion, exclusive breastfeeding for the first six months of life supported adequate growth for the infants studied. Early introduction of complementary feeding particularly before four months resulted in frequent illness episodes and growth faltering. Health workers are encouraged to continue to correct misconceptions concerning the sufficiency of exclusive breastfeeding for the first six months of life through antenatal and postnatal education about the physiology of lactation. Mothers should be supported and encouraged to breastfeed exclusively for as long as possible and preferably for the first six months of life. During this period efforts should be made to ensure that the mothers have better access to health services and information.

\section{REFERENCES}

1. Grant, J.P. The State of the World's children 1998: UNICEF, Oxford University Press 1999; 96.

2. WHO. The WHO/UNICEF approach to integrated management of childhood illness: Update. Bull. World Hlth. Org. 1995; 73:735-740

3. Nabarro, D., and Chinock, P. Growth monitoring inappropriate promotion of an appropriate technology. Soc. Sci. Med. 1988; 26:941-948.

4. Grant, J.P. The State of the World's Children 1995: UNICEF, Oxford, Oxford University Press. 1995; 20.

5. Juez, G., Diaz, S., Casado, E., et al. Growth pattern of selected urban Chilean infants during exclusive breastfeeding. Amer. J. Clin. Nutr. 1983; 38:462-468.

6. Dualeh, K.A., and Henry, F.J. Breast milk. The life saver: Observations from recent studies. Food Nutr. Bull. 1989; 11:43-46

7. Martines, J.C., Rea, M., and De Zoysa, I. Breast feeding in the first six months. Brit. Med. J. 1992; 304;1068-1069.

8. De Zoysa, I., Rea, M., Martinez J. Why promote breastfeeding in diarrhoeal disease control programmes? Hlth Policy and Plann. 1991; 6:371-379.

9. Diaz S., Herrerros, C., Aravena, R., et al. Breastfeeding duration and growth of fully breast-fed in a poor urban Chilean population. Amer. J. Clin. Nutr. 1995; 62:371-376.

10. Newman, J. How Breast milk protects newborn. Sci Amer. 1995; 4:76-79.

11. Zumrawi, F.Y., and Diamond, H. Determinants of growth in the first 6 months of life among the urban poor in Sudan. J. Trop. Med Hyg. 1998; 91:139-146.

12. Victoria, C.G., Smith, P.G., Vaughan, J.P., et al. Infant feeding and deaths due to diarrhoea: A case control study. Amer. J. Epidemiol. 1989; 129:1032-1041.

13. Kramer, M.S., and Kakuma, R. Optimal duration of exclusive breastfeeding. Cochrane Database Syst. Rev. 2002; 1:CD003517.

14. Underwood, R.A., and Hofvander, Y. Appropriate timing for complementary feeding of the breastfed infant. Acta Paed. Scan. 1982; 294:3-32. 
15. Davies-Adetugbo, A.A. Sociocultural factors and promotion of exclusive breast-feeding in rural Yoruba communities of Osun State, Nigeria. Soc. Sci. Med. 1997; 45:113-125.

16. Sachdev, H.P.S., Krisna, J. Puri, R.K., Satyanarayana, I. and Kumar, S. Water supplementation in exclusively breastfed infants during summer months in the tropics. Lancet. 1991; 337:929-933

17. Villipando, S.F., Bytte, N.F., Wong, W.W., et al. Lactation performance of rural Mesoamerindians. Euro. J. Clin. Nutr. 1992; 46:337-348

18. Coward, W.A., Paul, A.A., and Prentice, A.M. The impact of malnutrition on human lactation: observations from community studies. Fed. Proc. 1984; 43:2432-2437.

19. Perez-Escamilla, R., Cohell, R.J., Brown, K.E., et al. Maternal anthropometric status and lactation performance in a low-income Honduran population, evidence of the role of infants. Amer. J. Clin. Nutr. 1996; 61:528-534.

20. Prentice, A.M., Goldbery, G.R., and Prentice A. Body mass index and lactation performance. Euro. J. Clin. Nutr. 1992; 48:S78-S89.
21. Ahn, C.H. and Maclean, W.C. Growth of the exclusively breastfed infants. Amer. J. Clin Nutr. 1980; 33:183-192.

22. Falcao Pimentel, V.A., Midlej, Joaquim, M.C., et al. Growth of children fed exclusively with breast milk during the first 6 months of life. Oficina Sanit Panam. 1991; 110:311-318.

23. Ricco, R.G., Nogueira-de-Almeicla, C.A., Del Ciampo, L.A., et al. Growth of exclusively breast-fed infants from a poor urban population. Arch Latinoam Nutr. 2001; 51:122-126.

24. Ogbonna, C., and Okolo, S.N. Complementary feeding practices and growth pattern in infants in Jos University Teaching Hospital, Jos, Plateau State. Nig. J. Clin. Prac. 1999; 2:15-18.

25. Cohen, R.J., Brown, K.H., Canhuati, J., Rivera, L.L., and Dewey, K.G. Effects of age of introduction of complementary foods on infant breast milk intake, total energy intake and growth: a randomised intervention study in Honduras. Lancet. 1994; 344:288. 